Article

\title{
Study on Industrial Integration Development of the Energy Chemical Industry in Urumqi-Changji-Shihezi Urban Agglomeration, Xinjiang, NW China
}

\author{
Guiling Wang ${ }^{1,2}$, Degang Yang ${ }^{1, *}$, Fuqiang $\mathrm{Xia}^{1}$ and Yannan Zhao ${ }^{1,2}$ \\ 1 Xinjiang Institute of Ecology and Geography, Chinese Academy of Sciences, Urumqi 830011, China; \\ kendra5016@163.com (G.W.); xiafq@ms.xjb.ac.cn (F.X.); zhaoyannan528@163.com (Y.Z.) \\ 2 University of Chinese Academy of Sciences, Beijing 100049, China \\ * Correspondence: dgyang@ms.xjb.ac.cn; Tel.: +86-991-7885346 \\ Academic Editor: Giuseppe Ioppolo \\ Received: 12 April 2016; Accepted: 13 July 2016; Published: 18 July 2016
}

\begin{abstract}
With industrial integration accelerating in domestic and foreign enterprise, industrial integration is becoming the only way for regional development to break through its bottleneck. Compared with advanced foreign enterprises, there exists a significant gap in regional industrial integration, especially in the urban agglomeration of the energy chemical industries of Urumqi-Changji-Shihezi in Xinjiang. Findings from field visits and quantitative analysis show that the energy chemical industry in urban agglomeration is in a state of dispersed distribution, serious convergence in industrial structure, low level of specialization, and weak collaborative relationships. These issues seriously hamper the sustainable development of urban agglomeration. Specific actions aimed at these problems and the development bottleneck mainly include the integration of industrial parks in the central city and integration orientation on the level of urban agglomeration. Only by speeding up the pace of industry integration can Urumqi-Changji-Shihezi's urban agglomeration maintain and improve its market competitiveness. Accordingly, it can promote innovation and sustainability in the energy chemical industry and improve the overall level of development.
\end{abstract}

Keywords: Urumqi-Changji-Shihezi urban agglomeration; energy chemical industry; industry integration; development suggestions

\section{Introduction}

Consolidation or integration is usually linked with industry and industrial organization. Bain [1] proposed that industrial integration was essentially market integration with enterprise as the main body and industry as the framework, including division of labor and collaboration on the enterprise level, the level of department and industry, and the regional level. Fergusson and Teicholz [2] defined integration as the flow of knowledge and information with the concrete exposition from three dimensions: vertical, horizontal, and time. Berger [3] thought that industry could be integrated and industrial structure adjusted through mergers and acquisitions, the scale expansion of self-organization, and recombination of the production and distribution system. Hurley [4] argued that industry integration was a way of changing organizational boundaries when the enterprise was facing change in environment conditions which could establish the mission of the industry or enterprise organization mission and make a profit. Industrial integration of major industrial countries abroad experienced development from horizontal integration to vertical integration and hybrid integration, as well as from industrial capital to financial capital, and a combination of both. With the deepening of the global economy and technology integration, and the social division of labor, exchange, cooperation, and competition increasingly broke through regional restrictions, the strengthening of relationships and cooperation between regions 
was unprecedented and the competition between regions became increasingly fierce. In this new situation of regional economic development, in order to achieve dominance in the fierce competitive market, different cities chose the development model of the metropolitan region and achieved common prosperity by coordination between cities, which has become an important strategy for any county or region to enhance their economic strength and ability to compete and to increase opportunities for development.

With the development of internationalization and the further development of industrial integration in emerging industries in recent years, industry integration has become a hot topic in the history of capital markets under the background of large macroeconomic industrial policies regarding the transformation of the mode of production and the adjustment of economic growth structure for our country. The integration of industry is the crucial route that must be taken in order to break through the bottleneck. Broadly considering both domestic and foreign research, some relevant scholars have mainly studied the integration of specific industries among similar or relevant industries. The tourism industry [5-8], for example, is integrated in the same region through scenic spot resources and material and intangible cultural resources. Others have focused on the macroscopic analysis of the regional industrial integration in different regions, such as the petroleum industry $[9,10]$, auto industry [11], iron and steel industry [12,13], mining industry [14,15], and non-ferrous metal industry [16]. These industries were integrated through highly efficient cross-regional division and cooperation. In addition, from the perspective of economic integration, the integration of the industrial chain, and space integration [17-21], scholars have discussed the key problems of urban agglomeration development on the optimization of industrial structure and complementary urban function.

Energy chemical industry is primarily the process of preparing secondary energy and chemical products through a chemical process by using coal, oil, and natural gas resources [22]. The energy chemical industry includes the exploitation of the petroleum and natural gas industries; oil processing, coking, and nuclear fuel processing; coal mining and washing; electric heat production and supply; chemical raw materials and chemical products; rubber products; and chemical fiber. In recent years, scholars have mostly focused on the industry chain, industrial transformation, and the industrial cluster surrounding the energy chemical industry. The industry chain is the value-added process of the final product or service produced by enterprises. Li and Yang [23] analyzed the dynamic balance between the energy chemical industry's internal activities and the external environment of Xi'an and the metropolitan area in detail by using the SWOT method (SWOT is abbreviation for strengths, weaknesses, opportunities, and threats: an analysis of a product made before it is marketed), and concluded that $\mathrm{Xi}^{\prime}$ an should develop and improve the energy chemical industry downstream and fine chemical industry, and expand the professional market of energy chemical products in the western suburbs of Xi'an in order to accelerate the industrial linkages between regions. Ren and Dong [24], based on the industry construction situation, analyzed the composition of the industrial chain including coal, oil, natural gas, and rock salt, and discussed the construction mode and optimization path of the energy chemical industry chain, providing some reference for the sustainable development of the energy chemical industry. Gao [25] put forward that it was critical for Shaanxi to innovate and accelerate industrial transformation and upgrading based on the challenges facing the energy chemical industry. Furthermore, the energy chemical industry is one of strong correlation, which can effectively promote and drive the development of the transportation, business, agricultural, and sideline industries, but also have considerable impact on the environment. Some scholars researched the development model, competitiveness, and the influence on the environment based on the characteristics of the energy chemical industry [26-30], and proposed corresponding development recommendations to promote coordinated and sustainable development of the energy chemical industry. One example is building an eco-industrial park, in which a network of firms and organizations works together to improve their environmental and economic performance.

The western area of China is abundant in hydropower, coal, oil, and gas resources. China's western development strategy and planning clearly gives priority to developing the energy chemical 
industry, accelerating the construction of major energy chemical projects, and promoting sustainable and harmonious development of the energy chemical industry. In 2013, the National Development and Reform Commission (NDRC) published a new national urbanization plan and offered to foster the development of urban agglomeration in the Midwest, including the Urumqi-Changji-Shihezi urban agglomeration as one of 10 regions on which to focus. The "12th Five-Year Plan" outline of autonomous regions proposed that the Urumqi-Changii economic zone-which is the core carrier of the Silk Road Economic Belt, with the new Euro Asia Continental Bridge as its main body-should focus on developing intensive processing of energy mineral resources, the manufacturing industry, strategic emerging industries, and the modern service industry.

Based on industry development goals, and subject to the characteristics of the chemical industry, the energy chemical industry is a large-scale capital-intensive and technology-intensive industry, and is obviously efficient in its concentration scale and strong in industry correlation, as well as the industry of water resources consumption and serious environmental pollution. Therefore, it is urgent to guide industry agglomeration of the coal-chemical and petrochemical industries, integrate the advantageous resources, centralize the layout from the perspective of urban agglomeration, and realize industrial scale in order to build an eco-industrial park and expand the production chain.

\section{Description of Study Area}

The Urumqi-Changji-Shihezi urban agglomeration (UCS), located in the northern foot of the Tianshan Mountain range and the southern edge of the Junggar Basin in Xinjiang, is the key area in the core region of the Silk Road Economic Belt. This region includes four cities and three counties: the cities of Urumqi, Changji, Shihezi, Wujiaqu, and the counties of Hutubi, Manas, and Shawan (Figure 1). It covers an area of approximately $63,800 \mathrm{~km}^{2}$, accounting for more than $21 \%$ of the area of the economic belt in the northern slope of Tianshan, and has a population of approximately 4.6 million, which is $20.3 \%$ of the total population in Xinjiang. In 2013, UCS's GDP was nearly $43 \%$ of the total GDP in Xinjiang, and it contributed more than 55\% of the total annual economic growth to the development of Xinjiang, with the urbanization rate as high as $60 \%$. UCS was the most active economic and urbanized region, and was also an indispensably important engine for leading economic and social development in Xinjiang. Among this urban agglomeration, the first index of Urumqi was 7.54. Economic output in Urumqi accounted for over $60 \%$ and local financial revenue was 40 billion yuan; Urumqi was a high central position of urban agglomeration, and its high level of functioning radiated to other cities.

Coal, oil, and natural gas are the superior resources in the UCS region, with the coal power and coal-chemical, petrochemical, and wind power industries as the key energy and chemical industries. The region is the important hub and intersection of the delivery pipes for oil and gas resources in Xinjiang. At the same time, with further openness to the west in China, flow of factors, industrial connection, and resource allocation among cities in the region are more frequent. As the leading city of urban agglomeration, Urumqi should guide development of the energy chemical industry with respect to key technology, management and marketing, scientific research, and equipment manufacturing. In accordance with the superiority of resources in the UCS region, and combined with the characteristics of the energy chemical industry, this paper mainly includes the coal mining and washing industry, the oil and gas industry, oil processing and coking, the nuclear fuel industry, the chemical industry, gas and electric heating, and the water production and supply industry. 


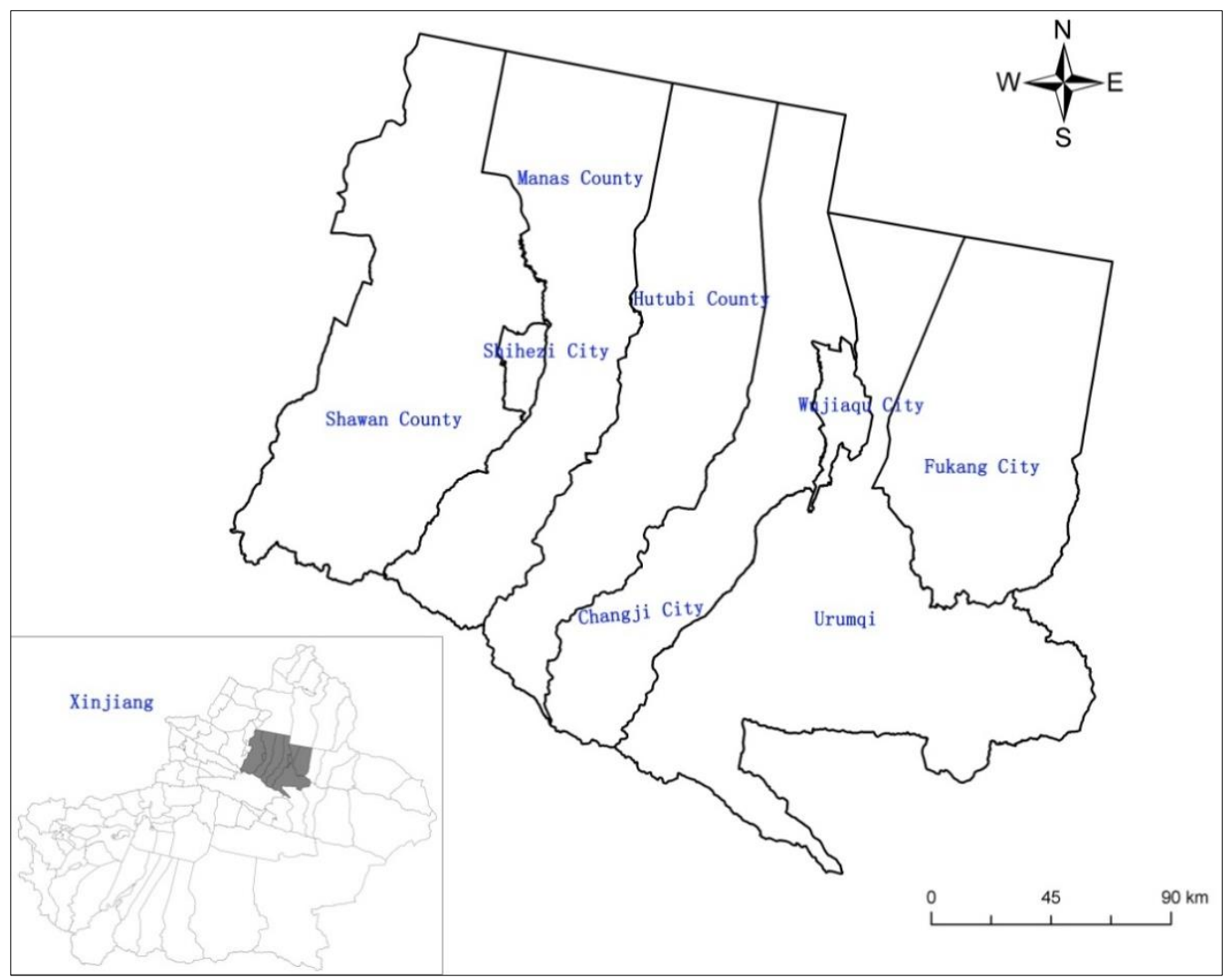

Figure 1. Study area.

\section{Analysis on the Integration of the Energy Chemical Industry}

\subsection{The Feasible Analysis of the Integration of the Energy Chemical Industry}

\subsubsection{The Advantageous Conditions of the Central City}

Urumqi is rich in a combination of resources in good condition. The coal resource is extremely rich. The Zhundong coalfield, where a group of enterprises owning exploration rights (such as Shenhua, Luneng, Huadian, LuAn, Shide, Yankuang) have established a presence, has reserves of about 213.6 billion tons. Zhundong is the especially colorful base of the coal-electricity and coal-chemical industry, and in the future will develop into a coal power and coal-chemical industry base of national and global importance. Urumqi is in the middle of three oilfields covering an area of $18 \mathrm{~km}^{2}$, which are rich in available oil resources and have comparatively perfect industrial chains. At the same time, the construction of China's onshore energy channel—including the China-Kazakhstan pipeline-will provide abundant petroleum for Urumqi. Dabancheng is rich in wind energy resources, with an area of over $5880 \mathrm{~km}^{2}$, and its comprehensive development scale reaches over 10 million kilowatts.

\subsubsection{The Unprecedented Strategic Opportunities Facing Urumqi Industry}

Under the strategic concept of the Silk Road Economic Belt autonomous region, the outline of the "12th Five-Year" Plan proposed that Urumqi focus on developing intensive processing of energy and mineral resources, manufacturing, strategic emerging industries, and a modern service industry. As the leading city, Urumqi has the function of integrating and guiding other cities. Moreover, the energy chemical industry, with a good development foundation and abundant resources, is currently the core industry promoting new industrialization and is the key to transformation of the advantageous resources. The future direction of the industrial transformation and upgrading of UCS urban agglomerations must take the lead in the Silk Road strategic channel to meet the needs 
of international strategy and seize the first opportunity to promote the development of industry consolidation and enhance the industrial competitiveness of the energy and chemical industry.

\subsection{Existing Problems in the Development of the Energy Chemical Industry of UCS Urban Agglomeration}

\subsubsection{The Short Energy Chemical Industry Chain and the Relatively Few Value-Added Products}

Of the products of major enterprises in the UCS urban agglomeration, the coal-chemical industry is mostly concentrated in the middle stage of the industrial chain, including coal liquefaction, coal gasification, synthetic ammonia, and polyvinyl chloride polymer (PVC). Petrochemical products using oil and natural gas as raw material—which have greater variety and a wider range—include petroleum refining upstream and the petroleum and chemical industry in the middle, including oil refining, aromatics, and ethylene. In addition, the downstream products are also involved in some leading enterprises, such as the Kunlun Tire Company in Xinjiang. Overall, subsequent product processing of the polymer materials is insufficient for extending to downstream, and there are fewer derivative products related to the energy chemical industry.

3.2.2. The Scattered Layout of the Main Energy Chemical Industry Parks in the UCS Urban Agglomeration

The industrial parks at different levels in the urban agglomeration have the problem of scattered layout and similar orientation of the leading industry, and they have not developed a specialized spatial agglomeration. For example, the Midong chemical industry park located in the north of Urumqi takes the oil, natural gas, chlorine-alkali, coal-chemical industry, new building materials, and mechanical manufacturing industries as the leading direction of industrial development. The Fukang heavy chemical industry park mainly develops coal power, coal char, coalification, electric power, and metallurgy. Hutubi county and Mulei county mainly process agricultural products and the coal-chemical industry. The north industrial park in Shihezi mainly develops the chlorine-alkali chemical, coal-electricity, coal-chemical, and building material industries. The contribution of industry development in other industrial parks is almost zero. Thus, the developing direction of the energy chemical industry in the urban agglomeration is similar. Some industrial parks have the division of labor and cooperation connection; however, there exists a certain degree of competition for the majority, which is not good for the coordinated development of the energy chemical industry in the UCS urban agglomeration.

\subsubsection{The Weak Relationship of Energy Chemical Industry Collaboration}

The relationship of the energy chemical industry collaboration between counties and cities is relatively weak. A connection of the energy chemical industry chain has not formed, and there exists the phenomenon of serious industrial isomorphism with a certain degree of competition (Table 1). The similarity coefficient of industrial structure can reflect the degree of development and maturity of the market among regions well. High industrial structure similarity can make the efficiency of resources allocation low, which will seriously influence the development of the economy [31]. The computation formula is as follows:

$$
S_{i j}=\frac{\sum_{k=1}^{n} X_{i k} X_{j k}}{\sqrt{\sum_{k=1}^{n} X_{i k}^{2} \sum_{k=1}^{n} X_{j k}^{2}}} 0 \leqslant S_{i j} \leqslant 1
$$

where $S_{i j}$ is the similarity coefficient of industrial structure between region $i$ and region $j$, and $X_{i j}$ and $X_{j k}$ are the proportion of department $k$ in region $i$ and region $j$, respectively. $S_{i j}$ changes within the range of $0-1$. The larger the coefficient, the more similar the industrial structure among regions and the lower the degree of specialization; the industrial structure among regions does not converge totally when $S_{i j}$ is zero; conversely, the lower the degree of similarity, the higher the degree of specialization. 
Table 1. The similarity coefficient of energy chemical industry structure in the Urumqi-Changji-Shihezi (UCS) urban agglomeration.

\begin{tabular}{cccccccc}
\hline & Urumqi & Changji & Fukang & Wujiaqu & Shihezi & Hutubi & Manas \\
\hline Urumqi & 0.767 & 0.998 & 0.938 & 0.814 & 0.839 & 0.806 \\
Changji & & 0.802 & 0.523 & 0.259 & 0.966 & 0.341 \\
Fukang & & & & 0.919 & 0.781 & 0.867 & 0.779 \\
Wujiaqu & & & & & 0.921 & 0.599 & 0.954 \\
Shihezi & & & & & & 0.420 & 0.858 \\
Hutubi & & & & & & 0.375 \\
\hline
\end{tabular}

The results show that the similarity coefficient of the energy chemical industry structure is almost above 0.8 , among which the similarity coefficient of Wujiaqu, Fukang, Shihezi, and Manas is over 0.9. From the microscopic view, the development of the energy chemical industry lacks overall layout, coordination, and interaction in the process of concrete operation, and there exists unreasonable competition and repeated construction, which attracts investment that is not conducive to the sustainable development of the energy chemical industry. Industry consolidation is urgently needed.

In recent years, the coal-electricity and coal-chemical industries of Changji developed rapidly, focusing on developing the new coal-chemical and coal power industries, including coal gasification, coal-to-oil, coal-to-olefin, and coal-to-fertilizer. In addition, there exists a certain difference in the energy chemical industry structure of Changji, Wujiaqu, Shihezi, and Manas, in which the similarity coefficient is almost below 0.5. The similarity coefficient between Shihezi and Changji is only 0.259. On the whole, UCS urban agglomeration has the basis and dynamic conditions of the chemical industry consolidation.

\subsection{The Developing State without Integration between Urumqi and Other Cities in Urban Agglomeration}

The location quotient (also called the specialization ratio) can reflect the degree of specialization in an industry sector of a certain area and the position and role in other areas. This paper analyzes the specialization level of the energy chemical industry in Urumqi using the location quotient theory. The computation formula is as follows:

$$
Q_{i k}=\left(X_{i k} / X_{i}\right) \div\left(Y_{k} / Y\right)
$$

$Q_{i k}$ is the location quotient; $X_{i k}$ is the output of industry $k$ in area $i$; $X_{i}$ is the sum of all industries' output in area $i ; Y_{k}$ is the total output of industry $k$; and $Y$ is the sum of the output of all industries.

The resource-based industries in Urumqi have developed rapidly, and the proportion of the industrial output continues to increase-especially in the coal mining and coal chemical industries-but they have failed to play a leading role in the high-end chain. In Xinjiang, the whole industry chain of Urumqi is short and the resource depth conversion is at a low level. Although the rough machining parts of resources in the development scale are obviously dominant, such as mining and the washing of coal, petroleum processing, and coking in upstream, the location quotients are less than 1 ; however, the development of chemical fiber manufacturing and rubber and plastics manufacturing industries in the downstream of the industry chain is relatively slow, and its location quotient is only 0.549 (Table 2), which is lower than the national average. Therefore, the specialization level of the energy chemical industry in Urumqi is not high, and industry advantage mainly reflects the economic scale rather than the economic quality. 
Table 2. Location quotients of the main energy chemical industries in Urumqi (derived from the 2014 statistical yearbook [32]).

\begin{tabular}{lc}
\hline \multicolumn{1}{c}{ Industry } & Location Quotient \\
\hline Mining and washing of coal & 0.735 \\
The exploitation industry of petroleum and natural gas & 0.800 \\
Oil processing and coking, processing industry of nuclear fuel & 0.804 \\
Chemical raw materials and chemical products manufacturing & 0.549 \\
Electricity, heat production, and supply industry & 1.792 \\
Production and supply of gas & 2.174 \\
\hline
\end{tabular}

\section{Concluding Remarks and the Space Layout Guidelines for Sustainable Development of the Energy Chemical Industry}

\subsection{Concluding Remarks}

Although the Urumqi-Changii-Shihezi urban agglomeration is rich in coal and oil resources, with the relative favorable industrial foundation of the energy chemical industry and perfect supporting facilities, there exists a certain degree of competition within industries and the serious problem of industrial structure convergence. Correlation indices are also low and the industry chain is short.

As the central city, Urumqi is in the central position concerning the whole industrial development level of the groups; however, its industrial specialization level is not high, so it fails to play a leading role in the high-end chain. Therefore, it is urgent to integrate the industry and for the central city to take the leading role in in promoting the coordinated development of Urumqi-Changji-shihezi economic integration.

Urumqi, which faces great national strategic demand, should take the whole industry framework of the energy chemical industry in the UCS urban agglomeration into full account, and promote effective organization among the industrial groups that need to cooperate in the energy chemical industry. Moreover, the government should fully support the central city in its leading and driving role, and strengthen the integrative development of the petrochemical and coal chemical, equipment manufacturing, and manufacturer-related service industries. Accordingly, the government can form a service system of energy chemical industry with the rational layout, orderly division of labor and coordination in place, achieving coordination and integration and highly specialized development of the energy chemical industry in the UCS urban agglomeration.

\subsection{The Space Layout Guidelines of the Energy and Chemical Industry}

\subsubsection{The Integration of Industrial Parks in the Central City}

As the core city of urban agglomeration, Urumqi has the advantage of leading the surrounding cities' industrial development through division of labor cooperation; therefore, the government should support Urumqi as the growth pole of urban agglomeration, build an eco-industrial park, and establish an effective coordination mechanism to integrate the energy chemical industry with the orientation of the chain, clustering, harmonization, ecological, diversified, and high-end development (Figure 2).

(1) New energy industry. The development of renewable energy is a national priority. Several priorities for moving forward have been identified, such as wind power, electric power, solar power, etc. It should be supported by high-tech industrial parks with Dabancheng at the core, relying on the chain advantage of the wind power industry in Urumqi to develop wind power equipment manufacturing and accelerate the construction of the wind power base in Dabancheng. At the same time, the solar industry should be steadily promoted to form the integrative production of the silicon industry-power station-chemical industry by building model bases of national renewable energy on a large scale, complete with a matching photovoltaic industry chain. 
(2) Coal-chemical industry. The Ganquanpu industrial park and Zhundong coal chemical industry base should be integrated to develop deeply processed products made from coal-made synthetic ammonia and polyethylene. Relying on the core technologies of coal liquefaction and gasification, synthesis gas purification, methanol synthesis, and methanol to olefins that have developed in China, along with the introduction, cultivation, and development of a batch of competitive large modern coal chemical enterprises both at home and abroad, we should actively promote the use and technology of coal resources, especially focusing on the development of coal-to-oil, coal-to-gas, coal-to-methanol, and coal to olefin, in order to promote the extension and development of the coal chemical industry chain.

(3) Petroleum and chemical industry. The focus should be on the Midong chemical industry park and economic and technological development zone in order to integrate the industry, developing both synthetic materials and organic materials, as well as the fine chemical industry, and building the important petrochemical base in northwest China. In addition, with respect to the Urumqi petrochemical company, it is important to integrate resources and industries by taking advantage of the three major oil fields in Xinjiang and the rich oil and gas resources in Central Asia. With the development, introduction, and application of high-level and new technology both at home and abroad, we should actively develop petroleum refining, polyester, aromatic hydrocarbons, synthetic materials, organic materials, and chemical materials. Additionally, by the maximum extension of downstream products, we should strengthen the industry oil chain to build a number of industrial chains of new chemical materials, including plastic, chemical fiber, rubber, and fine chemicals. Finally, we should form the type of industrial parks which have high-end organic chemical products and basic organic chemical raw materials with interrelated businesses, using supporting supply concentrations, highly efficient delivery logistics, and comprehensive recycling (Figure 3).

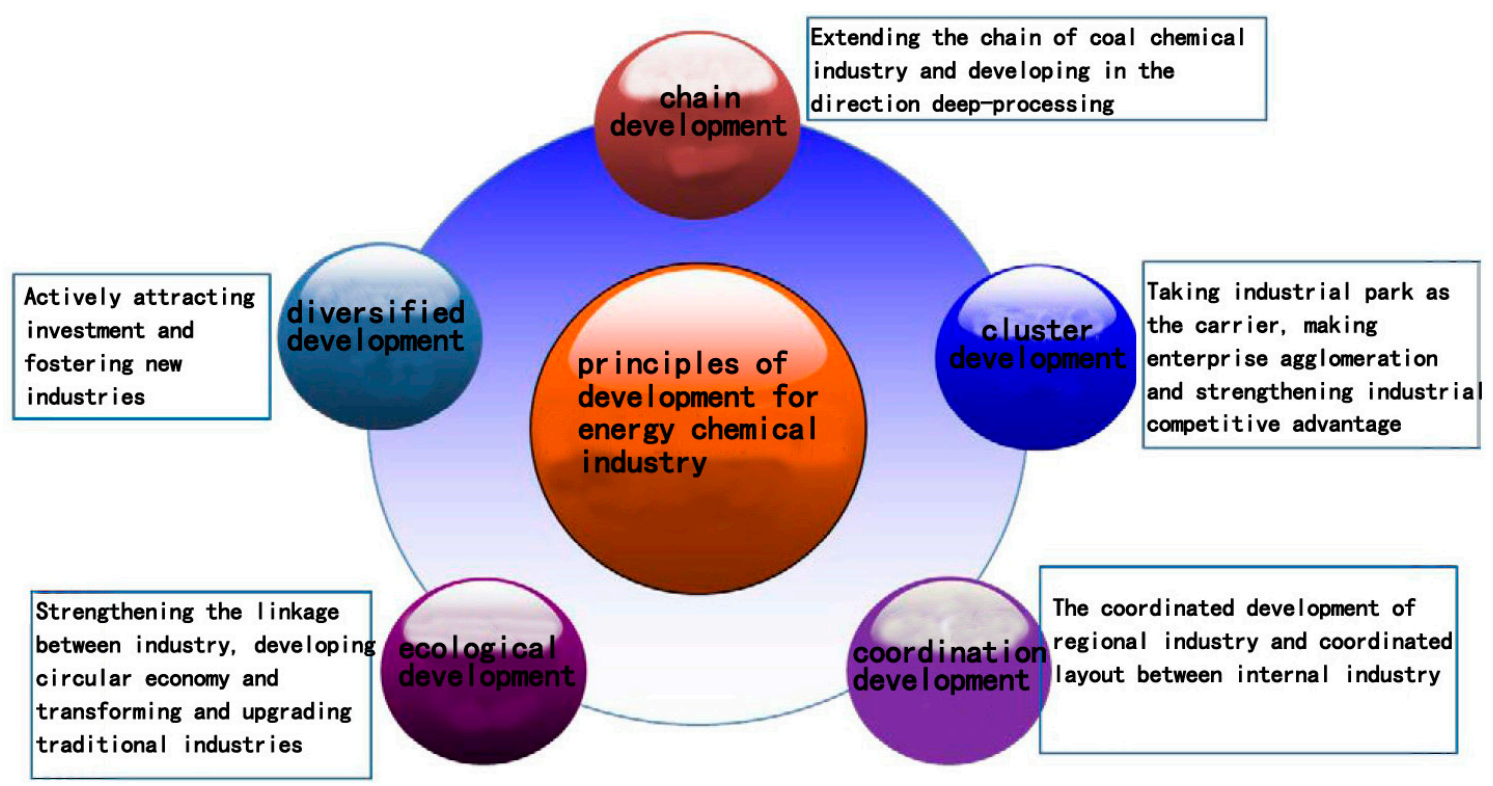

Figure 2. The principle of development for energy chemical industry. 


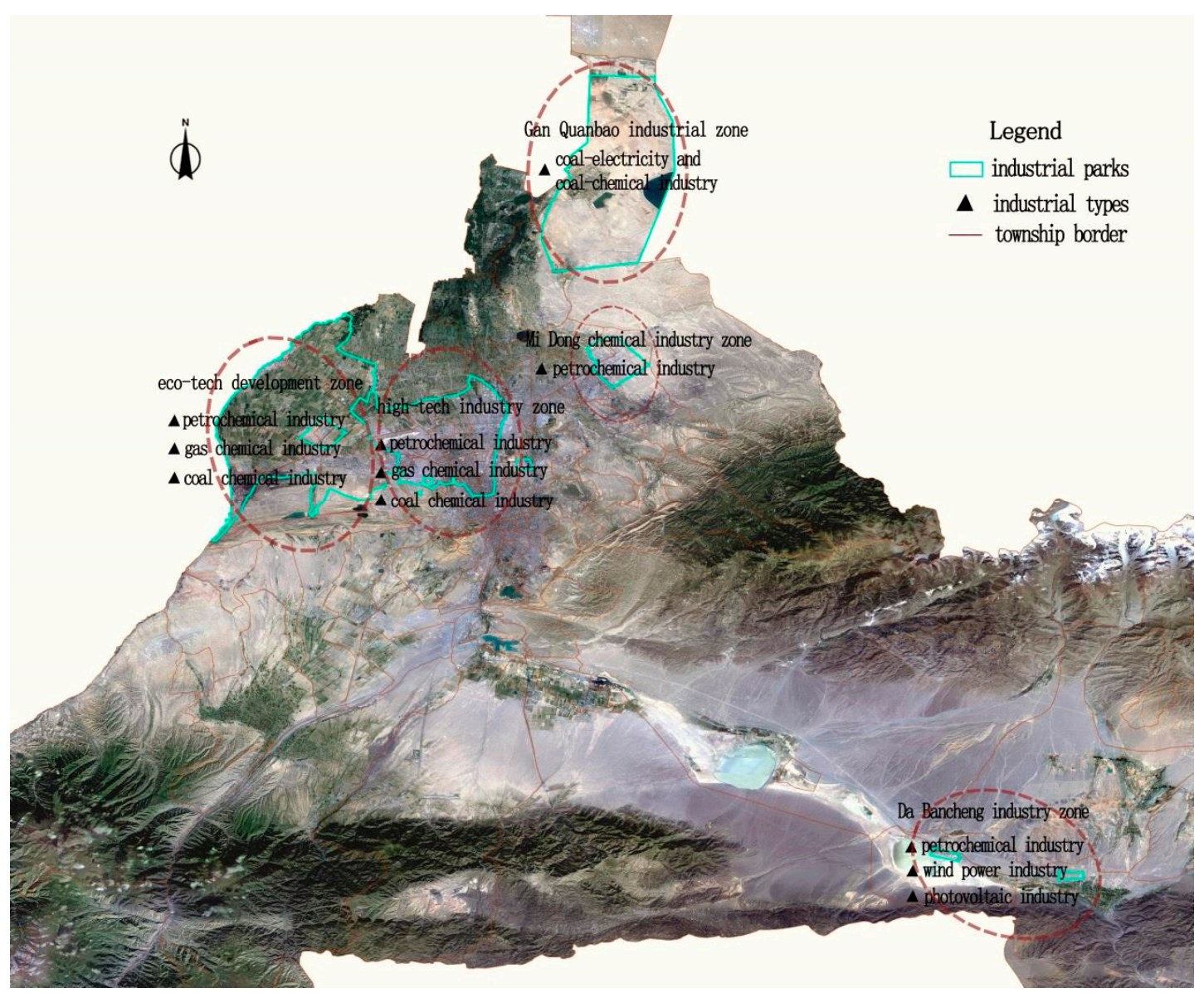

Figure 3. The direction of energy chemical industry consolidation in the main park of Urumqi.

\subsubsection{Integration Orientation on the Level of the Urban Agglomeration}

First, we can establish the research and development center-production base model for urban agglomeration and relocate the fine chemical industry to the high technology and economically developed zone of Urumqi. In this model, Urumqi would be a high-end research and development (R \& D) center, supporting other cities as a production base.

Second, we can develop the upstream and downstream extension model of the production chain. In the model, petroleum chemical industries would be located in Urumqi and Fukang and be reorganized by Urumqi Petrochemical Company, and coal power and the coal chemical industry would be gradually transferred to the surrounding Jimsar county. In addition, for the resident enterprises in the Midong chemical industry park, the scale and development direction of the product should be properly controlled, and at the same time, the chlorine alkali chemical industry should be relocated to Shihezi. Through those, we can jointly promote the conformity and coordinating development of the energy chemical industry between the central city and other cities in urban agglomeration.

Finally, relying on superior resources of the UCS urban agglomeration, we should drive the development of supporting enterprises through leading companies to realize the horizontal integration of the energy industry chain within urban agglomeration, and focus on the extensive ability and derivative ability of the industry chain to break through the energy industry and integrate the related auxiliary industries, such as the productive service and high-tech industries, including the information and logistics industries. Therefore, for the energy chemical industry, the weakness of high dependence on resources can be overcome to improve the ability to resist market risk. 


\subsubsection{Policy Recommendations at the Level of the Government}

In the process of energy chemical industry integration, the interests of the merged enterprises, local governments, and the local people will be involved. First, as the main body of organization and leadership, the governments at all levels of the urban agglomeration should balance the interests of all parties as far as possible, and harmoniously and orderly solve contradictions and problems according to the relevant laws and regulations, using the corresponding compensation mechanism. Second, the relevant leader should attract science-technology manpower at home and abroad and cultivate transferring technology and management talents with high quality. Finally, the government and related departments need to provide a favorable development space to restructure enterprises, giving full play to the leading role of the central city, and support and foster the leading enterprise with strength and potential. There are many ways to consolidate the energy chemical industry, including merger and acquisition, negotiating transfer, holding and joint-stock, and joint and reorganization, which can promote reasonable division of labor and cooperation within urban agglomeration, and create an orderly connection of the industry chain among different enterprises in order to enhance the entire development level of the energy chemical industry in the UCS urban agglomeration.

Acknowledgments: This work was supported by the Grant Program of Clean Development Mechanism Fund of China (CDMF) (No. 2014092), National Science and Technology Support Plan for the "12th five-year" (No. 2012BAC20B09), and the Auspices of the Special Scientific Research Fund of Environmental Protection Public Welfare Profession (No. 2012467044): the Key Technology Research on Risk Prevention and Control of Ecological Environment in the leapfrog development of Xinjiang. The authors sincerely thank the reviewers and editors. We also thank the cooperation of our anonymous respondents.

Author Contributions: Guiling Wang and Degang Yang designed research; Guiling Wang, Degang Yang and Fuqiang Xia performed research; Guiling Wang analyzed the data; All authors wrote the paper. All authors have read and approved the final manuscript.

Conflicts of Interest: The authors declare no conflict of interest.

\section{References}

1. Bain, J.S. Industrial Organization, 2nd ed.; M. John Wiley \& Sons Inc.: Hoboken, NJ, USA, 1968.

2. Fergusson, K.J.; Teicholz, P.M. Achieving Industrial Facility Quality: Integration is the Key. J. Manag. Eng. 1996, 12, 156-178. [CrossRef]

3. Berger, A. The Integration of The Financial Services Industry: Where are the Efficiencies? N. Am. Actuar. J. 2000, 4, 25-45. [CrossRef]

4. Hurley, D.T.; Santos, R.A. Exchange rate volatility and the role of regional currency linkages: The ASEAN case. Appl. Econ. 2001, 33, 1991-1999. [CrossRef]

5. Zheng, S. Rresearth on the urban leisure development based on the integration theory. Econ. Geogr. 2005, 25, $228-232$.

6. Shi, G. On Integration of Tourism Industry. Tour. Sci. 2005, 19, 14-18.

7. Chang, Y. On the Resources Integration \& Development of Cultural Tourism Industry in Shanxi; Shanxi University of Finance \& Economics: Shanxi, China, 2011. (In Chinese)

8. Sethuraman, R.; Sasiprabha, T.; Sandhya, A. An Effective QoS Based Web Service Composition Algorithm for Integration of Travel \& Tourism Resources. Procedia Comput. Sci. 2015, 48, 541-547.

9. Abraham, J.N.; Rao, K.S. Integration of generative and evaluative models for production scheduling of lube oil plants in a petroleum refinery. Appl. Math. Model. 2009, 33, 1213-1227. [CrossRef]

10. Nascimento, A.; Smith, D.H.; Pereira, S.A.; Sampaio, M.M.; Silva, M.A.; Mariani, A.M. Integration of varying responses of different organisms to water and sediment quality at sites impacted and not impacted by the petroleum industry. Aquat. Ecosyst. Health Manag. 2000, 3, 449-458. [CrossRef]

11. Li, W.; Duan, Q. Using Conformity Reorganization of the Automobile Industry to Enhance YI QI's Competitiveness. Technol. Econ. 2006, 25, 41-44.

12. Pan, K.; He, J. Trend analysis of integration mode of iron and steel industry in China. Contemp. Econ. 2012, 3, $70-72$. 
13. Ye, X. On the horizontal corporate merger and stackelberg game-taking the example of steel industrial integration in China. Mod. Financ. 2013, 8, 101-108.

14. Wang, F. Study on the Integration of Industry in Shanxi Province; Shanxi University of Finance \& Economics: Shanxi, China, 2011. (In Chinese)

15. Spallina, V.; Romano, M.C.; Chiesa, P. Integration of coal gasification and packed bed CLC for high efficiency and near-zero emission power generation Original Research Article. Int. J. Greenh. Gas Control 2014, 27, 28-41. [CrossRef]

16. Sun, L. A Study on China's Non-Ferrous Metal Industry Integration; Wuhan University of Technology: Wuhan, China, 2012. (In Chinese)

17. Li, L. The Research about Shanxi Tourism Industrial Chain Integration; Shanxi University: Shanxi, China, 2011. (In Chinese)

18. Zhou, Y.; Shen, H.; He, C. Economic Integration and Its Influencing Factors in the Wuhan Urban Agglomeration. Econ. Geogr. 2013, 33, 53-60.

19. Bergstrand, J.H.; Larch, M.; Yotov, Y.V. Economic integration agreements, border effects, and distance elasticities in the gravity equation. Eur. Econ. Rev. 2015, 78, 307-327. [CrossRef]

20. Venables, A. International Trade: Economic Integration. Int. Encycl. Soc. Behav. Sci. 2015, 23, 574-579.

21. Palma-Mendoza, J.A.; Neailey, K. A business process re-design methodology to support supply chain integration: Application in an Airline MRO supply chain. Int. J. Inform. Manag. 2015, 35, 620-631. [CrossRef]

22. Hu, X.; Wang, Z.; Li, Z. Challenges facing Chinese energy chemical industry and approaches to the solution (I). Chem. Ind. Eng. Prog. 2006, 25, 239-245.

23. Li, G.; Yang, Y. The research on the development strategy of energy chemical industry based on the division of labor in Xi'an. Mod. Manag. Sci. 2008, 8, 53-55.

24. Ren, Q.; Dong, H. Analysis of Energy Chemical Industry Chain of Yulin. Sci. Technol. Inform. 2013, 1, 418-419.

25. Gao, X. Consideration on the transformation development of energy and chemical industry in Shaanxi. Shaanxi Coal 2014, 2, 9-11.

26. Yan, Y. A Research on the Development Model of Northern Shanxi Energy and Chemical Industry Cluster; Xi'an Shiyou University: Xi'an, China, 2011. (In Chinese)

27. Bai, Y. Research on Competitiveness of Energy Chemical Industry Cluster in Yulin; Xi'an University of Science and Technology: Xi'an, China, 2012. (In Chinese)

28. Royne, F.; Berlin, J.; Ringstrom, E. Life cycle perspective in environmental strategy development on the industry cluster level: A case study of five chemical companies. J. Cleaner Prod. 2015, 86, 125-131. [CrossRef]

29. Rexhauser, S.; Loschel, A. Invention in energy technologies: Comparing energy efficiency and renewable energy inventions at the firm level. Energy Policy 2015, 83, 206-217. [CrossRef]

30. Walmsley, T.G.; Walmsley, M.R.W.; Atkins, M.J.; Neale, J.R. Integration of industrial solar and gaseous waste heat into heat recovery loops using constant and variable temperature storage. Energy 2014, 75, 53-67. [CrossRef]

31. Ran, Q. Empirical research on industrial division in Urumqi-changji region. J. Kashgar Teach. Coll. 2010, 31, 30-34.

32. Urumqi Bureau of Statistics. The 2014 Urumqi Statistical Yearbook; China Statistics Press: Beijing, China, 2014.

(C) 2016 by the authors; licensee MDPI, Basel, Switzerland. This article is an open access article distributed under the terms and conditions of the Creative Commons Attribution (CC-BY) license (http://creativecommons.org/licenses/by/4.0/). 